\section{I $\mathbf{B}$ A Institute of \\ YK Business Administration \\ 六下 \\ Karachi \\ Leadership and Ideas for Tomorrow}

Business Review

Volume 6 Issue 1 January-June 2011

$1-1-2011$

\title{
Role of information and communicational technologies in perceived organizational performance: An empirical evidence from higher education sector of Pakistan
}

\author{
Irfan Saleem \\ University of Central Punjab Lahore, Pakistan \\ Tahir Masood Qureshi \\ University of Central Punjab Lahore, Pakistan \\ Saba Mustafa \\ University of Central Punjab Lahore, Pakistan \\ Farooq Anwar \\ University of Central Punjab Lahore, Pakistan \\ Follow this and additional works at: https://ir.iba.edu.pk/businessreview \\ Part of the Communication Technology and New Media Commons, and the Higher Education \\ Commons
}

\section{(c) (;)}

This work is licensed under a Creative Commons Attribution 4.0 International License.

\section{Recommended Citation}

Saleem, I., Masood Qureshi, T., Mustafa, S., \& Anwar, F. (2011). Role of information and communicational technologies in perceived organizational performance: An empirical evidence from higher education sector of Pakistan. Business Review, 6(1), 81-94. Retrieved from https://doi.org/10.54784/ 1990-6587.1183

This article is brought to you by iRepository for open access under the Creative Commons Attribution 4.0 License and is available at https://ir.iba.edu.pk/businessreview/vol6/iss1/6. For more information, please contact irepository@iba.edu.pk. 


\title{
ARTICLE
}

\section{Role of Information and Communicational Technologies in Perceived Organizational Performance: An Empirical Evidence from Higher Education Sector of Pakistan}

\author{
Irfan Saleem, Tahir Masood Qureshi, Saba Mustafa \\ Farooq Anwar and Tahir Hijazi \\ University of Central Punjab Lahore, Pakistan
}

\begin{abstract}
This research study is an attempt to measure Impact of Information Communication Technology (ICT) on Organizational Productivity (Efficiency and Effectiveness); which leads to Organization Performance (DCost, $\Delta$ Time, and $\Delta$ Quality) using IRA Model. Study also explores barriers in ICT Adoption and impact of IT Literate Human Capital on Organizational Productivity. Sample for this research study has been chosen from Higher Educational Sector (HES) of Pakistan. These institutions are located at various geographic locations of Pakistan. Result shows significant relation of ICT adoption on the effectiveness, nonetheless ICT adoption is insignificant on efficiency; however the relationship between the two is positive. Research suggest that ICT adoption needs to be implemented with the intent of maximizing organizational outcome, in a manner that ICT fundamentally improves the Organizational Productivity of the firm, which, in turn will improve Organizational Performance.
\end{abstract}

\section{KEYWORDS}

ICT Role and Adoption Model (IRA) Model, Organization Productivity, Organizational Performance, Higher Education Sector (HES), Information Communication Technology (ICT), Core Communicational Technologies (CCT), Enterprise Computational Technologies (ECT), Group Collaboration Technologies (GCT), Organizational Efficiency and Organizational Effectiveness.

\section{BACKGROUND AND RATIONALE OF STUDY}

The Organizations of developing countries including Pakistan shall take into account Information Technology (IT) integration with their organizational structures seriously like some of the growing economies including Malaysia. A research form banking sector of Malaysia proves that IT is being adopted and accepted by Managers (Selamat and Jaffar, 2011). One of latest research (Aziz et al, 2010) shows 
that IT tools are being increasingly used in educational institutions of developed nations. In order to compete with industrialized countries in the same arena and face crucial challenge of survival, application of IT capital and new organizational structures are inevitable for third world countries. A great role that IT offers for firms in developing countries Gatautis (2008); instead the threat of downsizing policies (Foster and Heeks, 2010), they must ensure to make more of IT and labor complementarily in their organizations. It is also consistent with recent observed trends in the rapid adoption of Enterprise Resource Planning (ERP) systems (Tsai et al, 2010). IT is the current choice of many developing and developed countries to upgrade their economies and become competitive in the global market place (Shaukat et al, 2009). IT-based economies have streamlined the most complex economies of the world and enhanced the productivity to the level where developed economy has wriggled out of the entire trillion-plus dollars national deficit and turned into a surplus in recent years. To compete with the growing economies of the world, Pakistan needs to educate, train and bring its workforce to the international educational standards, incorporate new technologies and modern management practices into its industry, and bring intense focus on building an information-based economy by upgrading the technical and managerial skills of its people. Although Environment related factors often constrain the utilization of IT in developing countries such as Pakistan; nevertheless, research in Higher Education Sector (HES) of Pakistan (Shaikh, 2009) proves that ICT facilitates HESs of developing economies in narrowing global digital divide and thus producing knowledge-based societies which interns is improving quality of learning and educational outcomes. Computers and IT are basically used to transform the manual systems into automated systems; nonetheless, the pace of change of automation is slow in developing nations (Ahmed, 2006). The use of ICT is still limited to letter writing using world processing software (Ahmed et al, 2010) at most of Small and Medium Enterprises. Top line management is still stuck with the old trends of formal administrative practices and procedure (Gatautis, 2008) including the Higher Education Institutes themselves in developing Countries Shaikh (2009). Institutes are producing highly skilled and motivated IT professionals for the industries (Aziz et al, 2010) however institutes themselves are not getting full benefit (Shaukat et al, 2010; Saeed et al, 2010; Sultan, 2009). There is a great need of reformation of the managerial and administrative infrastructure of the academic institutions and the IT training of administrative personnel (Shaikh, 2009).

Why IT is not being adopted in HES of developing countries with the same pace as in many developed nations? There are many reasons behind this question. In fact, the people who are associated with these educational institutions and have worked throughout their lives in old legacy systems environment have not mentally accepted the advent of Information Technology. 
As it has been identified by a research that older and non-experienced employees have more computer anxiety (Sultan, 2009). They feel that machines and computers are replacing them, and so they put their most efforts in trying to prove that Information Technology is failed in this country, rather than putting their efforts in optimizing their own performance. Misperception that IT causes unemployment can be cleared by idea presented by research of Shaukat et al (2010) which detected increase in IT related jobs in banking and manufacturing sector due to recent automation. Lastly, the survival and growth of organizations in an increasingly turbulent environment would depend upon effective utilization of ICT (Lucchetti and Sterlacchini, 2004) for aligning the organizational structure with environmental preferences and for creating symbiotic inter-organizational structures.

\section{LITERATURE REVIEW}

Broad ranges of ICTs are being used in a variety of industries to improve Organizational Performance. To measure adoption impact of ICTs a definitional framework to distinguish among different types of ICTs that are typically used and being practiced. This definitional framework helps to relate various technology types to different kinds of improvement possible in organizational performance.

\section{INFORMATION TECHNOLOGY}

Information technology (IT) includes all types of technologies used to create, store, exchange and use information in its various forms including business data, voice conversations, still images, motion pictures, multimedia presentations and any other forms, including those not yet conceived (Poku and Vlosky, 2002). Alternatively, William and Sawyar (2005) elaborate IT as technology which facilitates to produce, manipulate process, store, communicate, and disseminate information. A sample of 700 respondents proves that that are fourteen (14) different types of information technologies that are commonly used for project management in information work settings (Bardhan et al., 2007).

\section{INFORMATION COMMUNICATION TECHNOLOGIES}

Information and Communication Technologies (ICTs) are modern instrumental tool that enables the educators to update the teaching methods (Mbaeze et al., 2010). ICTs are generally defined as information tool to create, process, transfer and share data (Saeed et al, 2010). For this research (Bardhan, 2005), basic independent variable is Information Communication Technologies (ICT), which is further subcategorized into three main groups including Core Communicational Technologies (CCT), Enterprise Computational Technologies (ECT) and Group Collaboration Technologies (GCT). CCT will include Email, Internet Search Engines, Mobile Communication; ECT will include Instant Messaging Software, 
Video-Conferencing Technologies, Groupware and Online Blogs. GCT will include Enterprise Application Software, Knowledge Management Software, Customer Relationship Management Software, Project Management Software, Business Intelligence and Document Management Solutions.

\section{ORGANIZATIONAL PRODUCTIVITY}

Productivity is a performance measure that includes efficiency and effectiveness (Robins et al, 2009). An organization will be productive, if it achieves its goals and does so by transferring inputs to outputs effectively and efficiency. Efficiency also refers to the degree to which an organization is able to more cost- and timeeffectively (Bardhan, 2005). The scope of this research study will include operational productivity using ICT and perceived organizational performance. Bardhan et al (2007) suggests that, Firm productivity is usually a ratio of firms' outputs divided by inputs.

\section{ORGANIZATIONAL PERFORMANCE}

Organizational performance often dependent on managers' skill of converting knowledge into action, nevertheless, Knowledge and information are obviously crucial to performance (Pfeffer and Sutton, 2000) and IT tools are playing significant role (Lucchetti and Sterlacchini, 2004; Shaikh, 2009; Ahmed, 2010) for improved organizational performance (Shaukat and Zafarullah, 2010) in Pakistan and other developing countries including Malaysia(Selamat and Jaffar, 2011). Choi et al (2010) conclude that organizations can improve team members' meta-knowledge through IT financing, nevertheless sharing of knowledge alone is not enough, organization must ensure application of shared knowledge for improved group performance, which intern can improve the organizational performance (OP). Statistical evidence shows that Firms are using IT to improve organizational performance in Pakistan (Shaukat et al, 2009). In order to quantify the outcome of research, outcome has been subcategorized in term of perceived change in Cost, Time and Quality, i.e. to measure the effect of ICT adoption on OP.

\section{IRA RESEARCH MODEL}

This research has developed an ICT Role and Adoption Model (IRA) Model, which provides distinction between Organizational effectiveness and Organizational efficiency while ICT is being adopted by the organization. IRA Model examines the impact of ICT Adoption on Organizational Productivity, which leads to Organizational Performance. In the model, the Dependent Variable is ICT which is further classified into CCT, ECT and GCT. The Independent Variable is Organizational Productivity (Efficiency, Effectiveness) and the Outcome variable of 
research is measured as Organizational Performance ( $\triangle$ Cost, $\triangle$ Time, and $\triangle$ Quality).

\section{FIGURE 1: IRA MODEL}

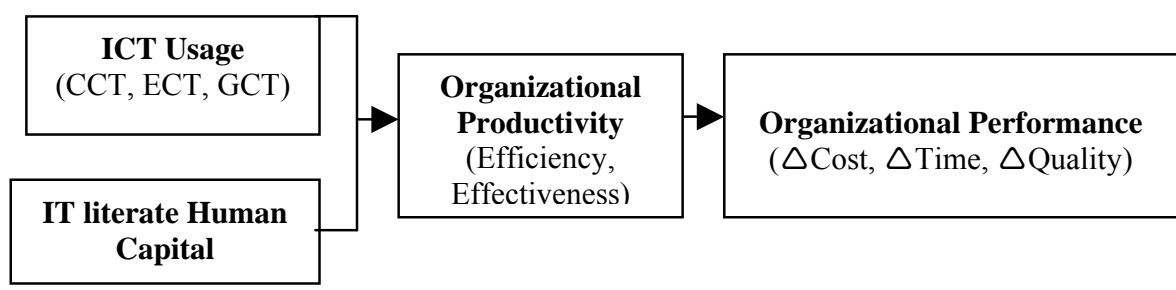

\section{THEORETICAL FRAME WORK OF IRA MODEL}

Broad range of variables can be used to identify and measure the Organizational Performance, Organizational Productivity and Informational Communication Technology.

\section{RESEARCH HYPOTHESIS}

In this research work, there are following three main hypotheses in consideration.

H1) Greater usage of ICT is associated with an improvement in perceived Organizational Productivity.

H2) Improvements in Organizational Productivity is associated with Organizational Performance.

H3) More the IT Literate Human Capital more will be Organizational Productivity (if ICT adopted).

Main hypothesis H1 can be further subdivided in two parts (H1A: Greater usage of ICT associated with an improvement in Organizational Effectiveness; H1B: Greater usage of ICT associated with an improvement in Organizational Efficiency). As there are three main subgroups of basic Independent Variable ICT (CCT; ECT; GCT). Consequently, research hypothesis H1A can be further stated in the parts (H1Ai: Greater CCT usage is associated with improvements in Organizational Effectiveness.; H1Aii: Greater ECT usage is associated with improvements in Organizational Effectiveness. H1Aiii: Greater GCT usage is associated with improvements in Organizational Effectiveness). The second part of main hypothesis $\mathrm{HIB}$, thus can also be rewritten in subparts (H1Bi: Greater CCT usage is associated with improvements in Organizational Efficiency; H1Bii: Greater ECT usage is 
associated with improvements in Organizational Efficiency; H1Biii: Greater GCT usage is associated with improvements in Organizational Efficiency).

The second hypothesis $\mathrm{H} 2$ of research model is significant in model (H2: Improvements in organizational productivity are associated with improvements in Organizational Performance). To quantify the research outcome, Organizational Performance is subcategorized into perceived change in Cost, Time and Quality which leads to three sub-hypothesis (H2A: Improvements in organizational productivity are associated with decrease in cost; H2B: Improvements in organizational productivity are associated with decrease in time to perform work or job done; H2C: Improvements in organizational productivity are associated with increase in Quality of work or job done). And above all hypotheses can further subcategorized (H2Ai: Improvements in organizational efficiency are associated with decrease in cost; H2Aii: Improvements in organizational effectiveness are associated with decrease in cost; $\mathrm{H} 2 \mathrm{Bi}$ : Improvements in organizational efficiency are associated with decrease in time to perform work or job done; H2Bii: Improvements in organizational effectiveness are associated with decrease in time to perform work or job done; $\mathrm{H} 2 \mathrm{Ci}$ : Improvements in organizational efficiency are associated with increase in Quality of work or job done; H2Cii: Improvements in organizational effectiveness are associated with increase in Quality of work or job done).

\section{DATA COLLECTION}

Questionnaire is used as main data collection tool to measure the variables of interest. Target population consists of the computer professionals, administrative staff and faculty members of Higher Education Institutes from various geographic locations of Pakistan, including Islamabad, Lahore, Rawalpindi, Peshawar, Multan, DG Khan and Faisalabad and some other cities. 290 questionnaires were sent through mails and emails from those only 120 were returned with $41.3 \%$ response rate. 94 Questionnaires were filled properly, out which

Main Higher Education Institutes of Pakistan representing 90\% of sample include University of ARID Agriculture (University Institute of Information Technology), Rawalpindi ,COMSATS Institute of Information Technology (Islamabad and Wah campuses),Muhammad Ali Jinnah University, Islamabad Campus, ZABIST Islamabad campus, AIR University Islamabad, Riphah School of Leadership, Bahria University Islamabad, Bahaduddin Zakariya University, Multan, Virtual University (Lahore, Rawalpindi, Peshawar, Islamabad and DG Khan Campuses), International Islamic University, Islamabad, Federal Urdu University, Islamabad, National University of Science and Technology, Punjab University Lahore, GC University ( Lahore, Faisalabad), University of Engineering and Technology Lahore, Peshawar University, University College of Education D.G. 
Khan, and Allama Iqbal Open University. SPSS (Statistical Package for the Social Sciences) has been used and applied for various statistical tests necessary for the reliability of this research.

\section{FINDINGS AND EMPIRICAL RESULTS}

\section{a) ROLE OF ICT IN ORGANIZATIONAL PRODUCTIVITY}

Results revealed in Table1, prove that both CCT and GCT have a significant positive $(r=0.246)$ relation with the perceived effectiveness. The impact of ECT on organizational effectiveness is positive but is not statistically significant $(\mathrm{r}=0.108)$, the reason might be that, these type of ICTs are not being adopted by organizations in Pakistani HES sector. Hence, the results support hypotheses H1Ai and H1Aiii, but do not fully support H1Aii. Inversely, results demonstrate that the ICT is very week but positive relation with perceived Efficiency.

\section{Table 1}

\begin{tabular}{|c|c|c|}
\hline Independent Variable & \multicolumn{2}{|c|}{ Dependent Variables } \\
\hline & Effectiveness & Efficiency \\
\hline CCT & $.246\left(^{*}\right)$ & .102 \\
\hline GCT & $.224\left(^{*}\right)$ & .050 \\
\hline ECT & .108 & .107 \\
\hline
\end{tabular}

* Correlation is significant at the 0.05 level (2-tailed).

\section{b) ORGANIZATIONAL PERFORMANCE AFTER ICT ADOPTION}

The impact of ICT on Organizational Performance is shown in Table2, which identifies impact of ICT adaptation on the Organizational Performance. Three variables outcome variables have been used to quantify the Organizational Performance (reduced cost, improved quality and better time). Results shows that adoption ICT has significantly contributed for better response time $(r=0.362)$, lesser cost $(\mathrm{r}=0.500)$, and improved quality $(\mathrm{r}=0.430)$ as for as perceived effectiveness is concerned. The efficiency of organization has also improved after adopting ICTs as better response time $(r=0.254)$, lesser cost $(r=0.273)$, and improved quality $(r=0.464)$ although this relation is weaker in comparison to effectives. 
Table 2

\begin{tabular}{|l|l|l|l|}
\hline & Time & Cost & Quality \\
\hline Effectiveness & $.362(* *)$ & $.500(* *)$ & $.430(* *)$ \\
\hline Efficiency & $.254(*)$ & $.273(*)$ & $.464(* *)$ \\
\hline
\end{tabular}

c) ROLE OF IT LITERATE HUMAN CAPITAL ON ORGANIZATIONAL PRODUCTIVITY AND PERFORMANCE

Impact of having IT Literate Human Capital in organization on perceived effectiveness is statistically strong and positive $(\mathrm{r}=0.417)$, nonetheless same is not true for the Efficiency $(\mathrm{r}=0.120)$.

Table 3

\begin{tabular}{|l|l|l|}
\hline & Effectiveness & Efficiency \\
\hline IT Literate HR Capital & $.417(* *)$ & .120 \\
\hline
\end{tabular}

** Correlation is significant at the 0.01 level (2-tailed).

\section{d) ROLE OF IT LITERATE HUMAN CAPITAL IN ORGANIZATIONAL PERFORMANCE}

On the other hand strong positive correlation between the Organizational Performance (reduced cost, better quality and improved response time) and IT Literate Human Capital has been identified as shown in Table 4.

Table 4

\begin{tabular}{|l|l|l|l|}
\hline & Time & Cost & Quality \\
\hline IT Literate HR capital & $.359(* *)$ & $.381(* *)$ & $.318(* *)$ \\
\hline
\end{tabular}

** Correlation is significant at the 0.01 level (2-tailed).

\section{e) BARRIERS IN ICT ADOPTION}

To measure barriers while adopting ICT in the Higher Educational Institutions of Pakistan, opinion of respondents was taken on different barriers. Statistics identifies only two main barriers. a) Problem of pirated or unregistered versions of software as $38.29 \%$ organizations are either agrees or strongly agreed that in Pakistan original software is the main issue of concern. b) The second main barrier is ICT expenditure is higher than expected of organization as $37.23 \%$ organizations are either agreed or strongly agreed that in Pakistan organization cannot afford initial high cost of ICTs. Our Study results shows inverse finding if 
compared with Sultan (2009) which proves that age and experience are the major significant correlates of computer anxiety as we find that top managers are basically interested in ICT adoption as $72.34 \%$ are either disagreed or strongly disagreed with first barrier in table 5. Nonetheless finding are somewhat consistent with Ahmed (2006).

TABLE 5: BARRIERS IS ICT ADOPTION

\begin{tabular}{|l|c|c|c|c|c|}
\hline \multicolumn{1}{|c|}{ Barriers } & $\begin{array}{c}\text { Strongly } \\
\text { Agree }\end{array}$ & Agree & Neutral & Disagree & $\begin{array}{l}\text { Strongly } \\
\text { Disagree }\end{array}$ \\
\hline $\begin{array}{l}\text { Top management is not } \\
\text { interested }\end{array}$ & $5.32 \%$ & $8.51 \%$ & $13.83 \%$ & $35.11 \%$ & $37.23 \%$ \\
\hline $\begin{array}{l}\text { Employees are } \\
\text { unwilling to use ICT or } \\
\text { Computer }\end{array}$ & $6.38 \%$ & $11.70 \%$ & $10.64 \%$ & $41.49 \%$ & $29.79 \%$ \\
\hline $\begin{array}{l}\text { New versions of } \\
\text { existing software are } \\
\text { introduced too often / } \\
\text { unavailable }\end{array}$ & $5.32 \%$ & $17.02 \%$ & $25.53 \%$ & $39.36 \%$ & $11.70 \%$ \\
\hline $\begin{array}{l}\text { The level of ICT skills } \\
\text { is too low among the } \\
\text { employed personnel }\end{array}$ & $9.57 \%$ & $15.96 \%$ & $17.02 \%$ & $42.55 \%$ & $14.89 \%$ \\
\hline $\begin{array}{l}\text { Difficult to find } \\
\text { qualified ICT personnel } \\
\text { or Computer } \\
\text { Professionals }\end{array}$ & $3.19 \%$ & $12.77 \%$ & $17.02 \%$ & $42.55 \%$ & $24.47 \%$ \\
\hline $\begin{array}{l}\text { No significant benefits } \\
\text { for the enterprise to use } \\
\text { ICT / Computer }\end{array}$ & $0.00 \%$ & $5.32 \%$ & $20.21 \%$ & $43.62 \%$ & $30.85 \%$ \\
\hline $\begin{array}{l}\text { Risk of viruses or } \\
\text { hackers accessing } \\
\text { confidential company }\end{array}$ & $6.38 \%$ & $19.15 \%$ & $23.40 \%$ & $34.04 \%$ & $17.02 \%$ \\
\hline $\begin{array}{l}\text { Technically too } \\
\text { complicated }\end{array}$ & $3.19 \%$ & $10.64 \%$ & $22.34 \%$ & $39.36 \%$ & $24.47 \%$ \\
\hline $\begin{array}{l}\text { Lack of perceived } \\
\text { benefit from ICT } \\
\text { Application or usage of } \\
\text { Computer }\end{array}$ & $5.32 \%$ & $12.77 \%$ & $25.53 \%$ & $36.17 \%$ & $20.21 \%$ \\
\hline $\begin{array}{l}\text { Problem of pirated or } \\
\text { unregistered versions } \\
\text { of software }\end{array}$ & $9.57 \%$ & $28.72 \%$ & $22.34 \%$ & $28.72 \%$ & $10.64 \%$ \\
\hline
\end{tabular}




\begin{tabular}{|l|c|c|c|c|c|}
\hline $\begin{array}{l}\text { ICT expenditure higher } \\
\text { than expected }\end{array}$ & $9.57 \%$ & $24.47 \%$ & $28.72 \%$ & $25.53 \%$ & $11.70 \%$ \\
\hline
\end{tabular}

\section{DISCUSSION, CONCLUSION AND FUTURE RESEARCH}

Firstly, Research objectives included identification of ICT adoption acceptance role in Organizational Productivity, and Organizational Performance. Secondly, once ICT has adopted by organization, what role IT Literate Human Capital shall play in Organizational Productivity \& Organizational Performance. Finally, research explores possible barriers if any in ICT Adoption.

Research suggests that ICT needs to be implemented with the intent of maximizing organizational outcome, in a manner that fundamentally improves the Organizational Productivity of the firm, which, in turn, will improve Organizational Performance. These findings are consistent with Selamat and Jaffar (2011) proving that shows that perceived usefulness, management support and external computing support are the most influential factors in determining microcomputer usage among bankers in Malaysia. $\left(r^{2}=0.396\right)$. In depth this study is partially consistent with Bardhan (2005) as correlation values of ECT $(\mathrm{r}=0.300)$, GCT $(\mathrm{r}=0.05)$ and $\mathrm{CCT}(\mathrm{r}=0.23)$ in relation to effectiveness are closely related.. Organizations will not realize significant performance improvements if ICT adoption is used to improve quantity of outputs and inputs, ignoring the effectiveness or quality of the outcomes. Effectiveness should be as much of a focus as efficiency, which has hitherto driven ICT investment decisions. Study findings amplify the need for firms to strengthen their organizational Productivity after making investments in Information Communication Technology these finding are consistent with Shaukat and Zafarullah (2010) who shows that Pakistani organizations are also adopting IT by making heavy investments in banking sector ( $23.34 \%$ of income), similar trend is required in HES sector of Pakistan. The study is also consistent with the finding or various studies regarding role of ICT adoption in improving organizational performance (Shaukat et al, 2009; Shaukat and Zafarullah, 2010).

This Research study has several limitations. First, the sample is taken from IT Literate staff and faculty and does include opinion form the staff of other disciplines of arts, basic, applied and pure sciences of institutes because of very less understandings of technologies and terms used in the research questionnaire. Secondly, the questionnaire might not be well understood by the lower level, less educated and remote areas staff members of the institutes, which may cause ambiguity in the findings. Thirdly, some of the institutes' management didn't cooperate to provide sample and simply refused to fill even one questionnaire, which may also cause variation on finding of the research. Fourthly, some of the employees were asking to pay per questionnaire, which was a valid demand to sacrifice time for 
individual opinions but data was not collected from that population due to limitation of financial resources. Lastly, perceived change in Cost, Time and Quality has been measured, instead of actual ones. For example, one can use exact financial measures like Return on Asset, Return on Equity to measure Cost and similarly for Time and Quality which is recommended for future research. Future research can be conducted on different sector including Banking Telecommunication, Textile, Software Houses or pure IT industry and one can be presented sector-wise comparison of Impact of

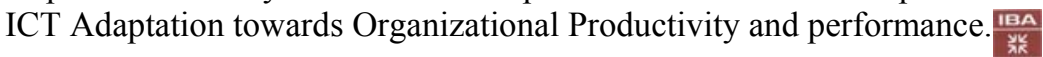

\section{REFERENCES}

Ahmed I., Shahzad A. and Umar M. (2010), "Information Technology and SMEs in Pakistan", International Business Research, Vol. 3(4), pp. 237-240

Ahmed I. (2006), "Significant barriers to ICT adoption in the public sector in the Least Developed Countries (LDCs): A case study of Bangladesh". 17th Australasian Conference on Information Systems (ACIS 2006 Proceedings), Paper 105

Aziz T., Khan Mo. B. and Singh Raj (2010), "Effects of Information Technology Usage on Student Learning: An Empirical Study in the United States", International Journal of Management, Vol. 27(2), pp. 205-217

Bardhan I. R., Krishnan V. and Lin S. (2007), "Project Performance and the Enabling Role of Information Technology: An Exploratory Study on the Role of Alignment", M\&SOM: Manufacturing and Service Operations Management, Vol. 9(4), pp. 579-595

Bardhan I., Krishnan V., Lin S. (2005), “A Model to Measure the Business Value of Information Technology: the Case of Project and Information Work", Working Paper, Rady School of Management

Choi S. Y., Lee H. and Yoo Y. (2010), "The Impact of Information Technology and Transitive Memory Systems on Knowledge Sharing, Application, and Team Performance: A Field Study", MIS Quarterly, Vol. 34(4), pp. 855-870

Foster C. and Heeks R. (2010), "RESEARCHING ICT MICRO-ENTERPRISE IN DEVELOPING COUNTRIES: THEMES, WIDER CONCEPTS AND FUTURE DIRECTIONS", The Electronic Journal on Information Systems in Developing Countries, Vol 43(7) pp. 1-20

Gatautis R. (2008), "The Impact of ICT on Public and Private Sectors in Lithuania", Engineering Economics. Vol. 4 (59), pp. 18-28 
Lucchetti R, and Sterlacchini A. (2004), "The Adoption of ICT among SMEs: Evidence from an Italian Survey", Small Business Economics, Vol. 23, pp. 151-168

Mbaeze I. C., Ukwandu E. and Anudu C. (2010), "The Influence of Information and Communication Technologies on Students' Academic Performance", Journal of Information Technology Impact, Vol. 10(3), pp. 129-136.

Pfeffer J. and Sutton R.I. (2000), "The Knowing-Doing Gap: How Smart Companies Turn Knowledge into Action”, Harvard Business School Press, Boston, MA, pp.243

Poku. K., and Vlosky R.P. (2002), "A Model of the Impact of Corporate Culture on Information Technology Adoption", Working Paper \#57, Louisiana Forest Products Laboratory, School of Renewable Natural Resources, Louisiana State University Agricultural Center, Baton Rouge, LA

Poku. K., and Vlosky R.P. (2003), “A Model of Marketing Oriented Corporate Culture Influences on Information Technology Adoption, Working Paper \#63, Louisiana Forest Products Development Center

Robbins P. S., Coulter M. and Vohra N. (2009), "Chapter 1: Introduction to Management and Organizations", Management 10th ed.: In Pearson Education, Inc. Publishing as Prentice Hall, pp 2-21

Saeed S. and Rohde M. and Wulf V. (2010), "An Empirical Study of IT use in Pakistani Civil Society Organizations", Communications in Computer and Information Science, Vol. 111, pp. 521-527

Selamat Z. and Jaffar N. (2011), "Information Technology Acceptance: From Perspective of Malaysian Bankers", International Journal of Business and Management, Vol. 6(1), pp. 207-217

Shaikh Z. A. (2009), "Usage, Acceptance, Adoption, and Diffusion of Information \& Communication Technologies in Higher Education: A Measurement of Critical Factors", Journal of Information Technology Impact, Vol. 9(2), pp. 63-80

Shaukat M. and Zafarullah M. (2010), "Impact of Information Technology on Organizational Performance: An analysis of Quantitative Performance Indicators of Pakistan's Banking and Manufacturing Companies", International Research Journal of Finance and Economics, Issue 39, pp. 229-243

Shaukat M., Zafarullah M.and Wajid R.A. (2009). "Information Technology in Pakistan: An Analysis of Problems Faced in IT Implementation by Pakistan's Banking and Manufacturing Companies", Pakistan Journal of Social Sciences (PJSS), Vol. 29 (1), pp. 13-22 
Sultan S. (2009), "Correlates of Computer Anxiety among Employees", Pakistan Journal of Social Sciences (PJSS), Vol. 29(2), pp. 293-300

Tsai W., Chen S., T.Y. Hwang E. and Jui-Ling Hsu J. (2010), "A Study of the Impact of Business Process on the ERP System Effectiveness", International Journal of Business and Management Vol. 5(9), pp 26-37

William B.K. and S.C. Sawyar (2005), "Using Information Technology", 6th edition, McGraHill Publishing Co. U.S.A: pp. 3, 4 and 147

The possible cultural interpretation of the temporal focus of human life break easily, even on a common sense basis, into the three point range of Past, Present, and Future. Obviously all societies at all times must cope with all three time problems; all must have their conceptions of the Past, the Present and the Future. Where societies differ in the rank-order emphasis they give to each, and a very great deal can be told about the particular society being studied, much about the direction of change within it can be predicted, of one knows what that rank order is. Spengler, greatly impressed by the significance of the time orientation, made this statement in his Decline of the West: "It is by the meaning that it intuitively attaches to time that one culture is differentiated from another."

Edward A. Tiryakia, Sociological theory, Values, and Sociocultural Change pg 223-224. 
Perhaps it is too soon, perhaps it will always be too soon, to try to formulate an adequate definition of man. Perhaps the fact that he is indefinable by his own mind is an essential fact about him. But we might, at least, consider more frequently than we do those of his characteristics which we have got into the habit of thinking about very seldom. We might, to begin with, ask concerning the calculating machine those questions posed earlier, and then add some more. Is it capable, we might ask, of imagination? Does it have any curiosity? Can it sympathize with anything? Can it be happy or miserable? Was it even to laugh, or even to show, by any unwonted flickering in its tubes, that it considered something amusing? Does it and this is most important of all - prefer one thing to another, or does it have its being in a universe where nothing has value, where all things are indifferent?

Joseph Wood Krutch, The Measure of Man, pg 169 